\title{
An empirical study on the relationship between effective organizational communication and the performance of central office staff
}

\author{
Abbas Monavvarian ${ }^{\mathrm{a}}$ and Golnaz Mehdi Asri ${ }^{\mathrm{b}^{*}}$
}

${ }^{a}$ Department of Management, University of Tehran, Tehran, Iran

${ }^{b}$ MBA with a strategic management orientation of Nonprofit virtual Farabi Institute of Higher Education-Member of Iranian Management System Company (SAMA)

\begin{tabular}{l}
\hline A R T I C L E I N F O \\
\hline Article history: \\
Received March 2, 2012 \\
Received in Revised form \\
May, 8, 2012 \\
Accepted 10 May 2012 \\
Available online \\
May 14 2012 \\
\hline Keywords: \\
Inter-organizational \\
communication \\
Efficiency \\
Effectiveness \\
Bank Melli Iran
\end{tabular}

\begin{abstract}
A B S T R A C T
Inter-organizational communication plays an important role in promoting strategic collaboration among firms. It can improve productivity and increases collaboration among employees. In this paper, we present an empirical study to measure the role of interorganizational communication on efficiency among administration employees who work for one the oldest banks in Iran, Bank Melli Iran. The study uses 380 full time employees who work for 28 different administration divisions of this bank. The survey uses a questionnaire consists of 19 questions about inter-organizational communication and 25 questions about efficiency of employees. The reliability of the survey has been approved using an initial survey and Cronbach alpha was calculated as 0.87 , which is well above the minimum acceptable level. The result of our survey confirms there is a meaningful relationship between interorganizational communication and efficiency of all administration employees who work for this bank. There is also a meaningful relationship between age and efficiency and the maximum efficiency belongs to people aged 31 to 40 . According to our survey, men have more interorganizational efficiency than women do. The result of our survey also confirms that positivism impacts more than other factors on efficiency. Among five effective factors, empathy has the most impact and responsiveness 6 efficiency dimensions.
\end{abstract}

\section{Introduction}

Inter-organizational communication plays an important role in promoting strategic collaboration among firms (Cameron \& Whetten, 2010; Terence et al., 1988). Paulraj et al. (2008) performed an investigation in supply chain management by studying the antecedents and performance outcomes of inter-organizational communication. Paulraj investigated the inter-organizational communication and its effect as a relational competency as a strategic advantages for supply chain partners. They used structural equation modeling to test a number of hypothesized relationships based on a sample of over 
200 United States companies. They reported some evidences for the notion of inter-organizational communication as a relational competency, which enhances buyers' and suppliers' performance.

Harvey et al. (2000) explained the consequences of globalization of business, which leads in the emergence of hyper-competition in various firms. These days, we see many organizations with different branches located in various geographical locations where many inter organization communications must happen over internet facilities such as email or other similar services. In fact, inter-organizational relationships have created motivation among many people to improve coordination and communication among the members of the global network. Harvey et al. (2000) developed the concept of 'timescapes' to help effective inter-organizational and inter-cultural communications. Neill and Rose (2006) performed an empirical investigation on the impact of strategic complexity on marketing strategy and organizational performance and reported that the proposition that strategic complexity was an organizational capability, which enabled more important strategy making and produces superior firm performance.

Many people believe that a positive approach may help increase performance of employees and Cravens et al. (2010) performed an empirical survey to test this. They explained that many organizations normally depend on performance evaluation measures to receive feedback to managers based on the achievement of strategic objectives. They explained that performance evaluation had been concentrated on negative effects of performance, recommending that managers might not be achieving necessary reinforcement of the positive elements of their decisions. According to Cravens et al. (2007), performance measures not only generate enough motivation, but also help communication and the exchange of necessary information among managers when it is applied properly. Under such circumstance, individual managers may reach their personal objectives, while the organization satisfies its strategic goals. The application of positive organizational scholarship rules on performance evaluation metrics can assist us to make the evaluation process, more effectively. They explain that using performance measures framed in a positive form normally helps create more creativity, more problem-solving ability, and wider communication among managers, leading to progress towards organizational goals.

Abili et al. (2011) investigated the role of effective factors on organizational knowledge sharing. They performed an investigation on effective factors on knowledge sharing in the Institute for International Energy Studies. They extended the results of Lin (2008), where three factors of organizational structure, organizational culture and interaction among departments were reported to have positive effect on knowledge sharing. They reported that first, the situation of knowledge sharing is rather desirable, second age, work experience, field of study, educational level and organizational position did not have any influence on knowledge sharing and knowledge sharing had a positive relation with human factors and negative relationships with structural factors. They also recommended that there was a positive relationship among knowledge sharing, creative and supportive culture and negative relationship between knowledge sharing and bureaucratic culture.

These days, teamwork plays an essential role on the success of firms and there are many studies, which measure the impact of teamwork. Sung and Choi (2012) studied the impacts of team knowledge management on the creativity and the performance of organizational teams in some Korean insurance companies. They reported that team knowledge utilization was positively associated with team creativity, which in turn forecasted team financial performance over a 6-month period. The positive influences of knowledge utilization were more important when team leaders maintained a systematic cognitive style and when teams were under uncertain circumstances. They also concluded that the systematic cognitive style of leaders impacted positively on team creativity and moderated the relationship between team knowledge stock and team creativity. 
Inter-communication consists of a process where a person sends a message to another in terms of different facilities such as sharing insights, believes, etc. Inter-communication consists of five main characteristics as follows,

- Openness: This factor includes in three communication tools such as face to face reaction.

- Empathy: This is one of the most difficult qualitative ways of communication, where sender and receiver both reach the same feeling.

- Supportiveness: This is a supportive relationship between two people.

- Positivism: This concept contains different perspectives and a person carries this feature while he thinks positive on himself. In other word, when a person thinks he is entitled to be treated with respect, he/she will be entitled to receive respect from other people.

- Equity: This is an especial item since we cannot find two people with precisely the same characteristics. People are different in terms of their intelligence, wealth, health conditions, etc.

Information technology plays an important role in increasing efficiency of organizations and it can help remove any physical borders among different countries and reduces physical transportation, significantly. Information and communication technology is more sophisticated application of advances in technology and it could increase decision making processes. The proposed study of this paper measures the relationship between inter-communication and efficiency among administration staff who work for Bank Melli Iran. The organization of this paper first presents the hypotheses of the survey in section 2 and details of the findings are given in section 3. The paper ends with concluding remarks to summarize the contribution of the paper.

\section{The proposed study}

The empirical study of this paper considers the following hypotheses,

1. There is meaningful relationship between effective organizational communication and employee's efficiency.

2. There is meaningful relationship between openness and employee's efficiency.

3. There is meaningful relationship between empathy and employee's efficiency.

4. There is meaningful relationship between empathy and employee's efficiency.

5. There is meaningful relationship between supportiveness and employee's efficiency.

6. There is meaningful relationship between empathy and employee's efficiency.

7. There is meaningful relationship between positivism and employee's efficiency.

8. There is meaningful relationship between equity and employee's efficiency.

9. There is meaningful relationship between effective communication and employee's properly accomplishing their duties.

10. There is meaningful relationship between effective communication and employee's properly following rules and regulations.

11. There is meaningful relationship between effective communication and increasing employee's efforts.

12. There is meaningful relationship between effective communication and increasing employees' interest in their jobs.

13. There is meaningful relationship between effective communication and increasing employees' responsibilities in their jobs.

14. There is meaningful relationship between effective communication and increasing employees' creativity in their jobs.

The study uses 380 full time employees who work for 28 different administration divisions of this bank. The survey uses a questionnaire consists of 19 questions about inter-organizational 
communication and 25 questions about efficiency of employees. The reliability of validity of the survey has been approved using an initial survey and Cronbach alpha (Cronbach, 1951) was calculated as 0.87 , which is well above the minimum acceptable level. The Cronbach alpha for effectiveness items were calculated as 0.88 for supportiveness, 0.81 for positivism, 0.78 for openness, 0.71 for empathy, 0.83 for equity, respectively. In addition Cronbach alpha were calculated as 0.75 for accomplishing duties properly, 0.83 for honering rules and regulations, 0.79 for employees' inerest in job, 0.81 for creativity, 0.81 for increasing people's efforts and 0.86 for responsibility, respectively.

In terms of gender characteristics, 57.4 persents of the participants in this survey was male and 42.6 percents was female. Nearly half of the participants aged between 31 and 40 and only $14.2 \%$ of the participants aged between 20 and 30. In terms of job experience, 57.1\% of the participants had from 11 to 20 years of job experience, 81.6\% of the participants had bachelour degree of science and only $0.5 \%$ of the participants had $\mathrm{PhD}$ degree. In terms of job position, $31.6 \%$ of the participants were working as staff and $10.8 \%$ of them were acting as chief. In terms of effectiveness attributes, $36.6 \%$ of the statistics was low, 53.4\% was on average level and the remaining $37 \%$ was high. In summary, we can conclude that organizational communication effectiveness was relatively low or around middle range. In terms of efficiency, $3.7 \%$ of this characteristics was considered low, $57.4 \%$ was on average level and 38.9\% was high. In other words, we can conclude that the efficiency was relatively high.

\section{The results}

We have used Freedman test, which is a nonparametric test to examine all hypotheses associated with organizational relationships effectiveness. Table 1 shows the summary of the results.

Table 1

The results of Freedmand test

\begin{tabular}{llllll}
\hline Attribute & Empathy & Positiveness & Supportivness & Openness & Equity \\
\hline Average rank & 3.31 & 3.02 & 2.94 & 2.94 & 2.86 \\
& Chi-square & 21.198 & $\mathrm{df}=4$ & sig $=0.000$ & \\
\hline
\end{tabular}

As we can observe from the results of Table 1, empathy maintains the highest impact among all figures followed by positiveness while supportivness, openness and equity are in other positions. We have performed the same Freedman test and Table 2 shows the summary of our results.

Table 2

The summary of Freedman test

\begin{tabular}{lllclll}
\hline Attribute & Responsiveness & $\begin{array}{c}\text { Interst in } \\
\text { job }\end{array}$ & $\begin{array}{c}\text { Rules \& } \\
\text { Regulations }\end{array}$ & $\begin{array}{c}\text { Increase in } \\
\text { employees' } \\
\text { efforts }\end{array}$ & $\begin{array}{c}\text { Creativity } \\
\text { Properly } \\
\text { accomplishing } \\
\text { duties }\end{array}$ \\
\hline $\begin{array}{l}\text { Average } \\
\text { rank }\end{array}$ & 4.47 & 4.19 & 3.82 & 3.23 & 3.04 & 2.86 \\
\hline & Chi-square & 4384.0 & $\mathrm{df}=5$ & sig=0.000 & & \\
\hline
\end{tabular}

As we can observe from the results of Table 2, responsiveness comes as the first priority, followed by employees' interest in their job, honoring rules and regulation, increase in employees' efforts, creativity and accomplishing duties, properly. We have also performed Pearson correlation tests among various factors and Table 3 shows the results. As we can observe from the results of Table 3 there is a meaningful relationship between effectiveness organizational communication and employees' efficiency. In other word, as the level of communication increases among employees, the level of efficiency among employees of banks increases too. 
Table 3

The results of Pearson test

\begin{tabular}{lcc}
\hline & Efficiency & Effective organizational relationships \\
\hline Efficiency & 1 & $.346\left(^{* *}\right)$ \\
\hline Effective organizational relationships & $.346\left(^{* *}\right)$ & 1 \\
\hline Openness & $.249\left(^{* *}\right)$ & $.760\left(^{* *}\right)$ \\
\hline Empathy & $.170\left(^{* *}\right)$ & $.707\left(^{* *}\right)$ \\
\hline Supportiveness & $0321\left(^{* *}\right)$ & $.907\left(^{* *}\right)$ \\
\hline Positivism & $0351\left(^{* *}\right)$ & $.882\left(^{* *}\right)$ \\
\hline Equity & $.334\left(^{* *}\right)$ & $.895\left(^{* *}\right)$ \\
\hline Accomplishing tasks & $.829\left(^{* *}\right)$ & $.219\left(^{* *}\right)$ \\
\hline Regulatory compliance & $.721\left(^{* *}\right)$ & $.231\left(^{* *}\right)$ \\
\hline Increased efforts & $.747\left(^{* *}\right)$ & $.379\left(^{* *}\right)$ \\
\hline Degree of interest in job & $.815\left(^{* *}\right)$ & $.359\left(^{* *}\right)$ \\
\hline Responsibility & $.796\left(^{* *}\right)$ & $.197\left({ }^{* *}\right)$ \\
\hline Creativity & $.857\left(^{* *}\right)$ & $.278\left(^{* *}\right)$
\end{tabular}

Based on the results we can summarize the following,

1. There is a positive and meaningful relationship among the components of communication effectiveness and participants have a relatively low average level of effectiveness calculated as $41.4 \%$.

2. Statistically, there is a positive and meaningful relationship between six efficiency components and the average is about $63.6 \%$, which is well above the average.

3. There is a positive relationship between organizational position and effective communication. The same holds between organizational position and independent efficiency variable. Note that people have different impacts on organization in terms of their position in organization. In fact, our results show $60 \%$ of the people who were in top management level were efficient but only $27.5 \%$ of the people who were in low level position were efficient. In terms of effectiveness communication components, using analysis of variance, managers maintained $55 \%$ average and regular employees maintained a low average of 36.9\%.

4. Our survey shows that there was a meaningful relationship between age and efficiency. The highest efficiency belonged to people aged 31 to 40 and the minimum belonged to people aged 20 to 30.

5. Our t-student test indicated that there was a meaningful relationship between effectiveness organizational communications between two groups of men and women and men contributed more than women do. Based on the results of our survey, $46.5 \%$ of the people with low level of organizational communication were women and $29.2 \%$ of them were men. In addition, $12.7 \%$ of the people who had a high level of organizational communication were men while only $6.4 \%$ of them were women.

6. The results of our survey shows a meaningful relationship among people with different educational level and people with $\mathrm{PhD}$ degree maintained higher level of performance compared with people with others.

7. The results of multi-variable regression estimates also show that the sense of positivism and the feeling of equity are accounted for $21 \%$ and $17 \%$ of efficiency, respectively. In other word, the more positive people mean the more effective people and more feeling of equity.

In summary, we can conclude that there are some personal characteristics, which play important role on increasing efficiency and effectiveness. On the other hand, we can observe that it is quite possible to increase women's efficiency by appointing them for management levels of works. People with low 
level of education could be encouraged to participate in short term or long term educational programs and increase their skills.

\section{Conclusion}

In this paper, we have presented an empirical study to the relationship between inter-organizational communication on efficiency and effectiveness of employees who work for public bank. The survey distributed two types of questionnaires among employees of the banks and analyzed the results using non-parametric tests. The result of our survey confirmed there was meaningful relationship between inter-organizational communication and efficiency of all administration employees who work for this bank. The results also confirmed that there was a meaningful relationship between age and efficiency and the maximum efficiency belongs to people aged 31 to 40. According to our survey, men have more inter-organizational efficiency than women do. The result of our survey also confirms that positivism impacts more than other factors on efficiency. Among five effective factors, empathy has the most impact and responsiveness 6 efficiency dimensions.

\section{Acknowledgment}

The authors would like to thank the officials of Bank Melli Iran for providing supports on this project.

\section{References}

Abili, K., Narenji Thani, F., Mokhtarian, F., \& Rashidi, M.M. (2011). The role of effective factors on organizational knowledge sharing. Procedia - Social and Behavioral Sciences, 29, 1701-1706.

Cameron, K., \& Whetten, D.A. (2011). Developing Management Skills. $8^{\text {th }}$ ed., Prentice Hall.

Cronbach, L. J. (1951). Coefficient alpha and the internal structure of tests. Psychometrika, 16(3), 297-334.

Cravens, K.S., Oliver, E.G., \& Stewart, J.S. (2010). Can a positive approach to performance evaluation help accomplish your goals? Business Horizons, 53(3), 269-279.

Lin, W.B. (2008). The effect of knowledge sharing model. Expert Systems with Applications, 34, 1508-1521.

Harvey, M., Griffith, D., \& Novicevic, M. (2000). Development of 'timescapes' to effectively manage global inter-organizational relational communications. European Management Journal, 18(6), 646-662.

Neill, S., \& Rose, G.M. (2006). The effect of strategic complexity on marketing strategy and organizational performance. Journal of Business Research, 59(1), 1-10.

Paulraj, A., Lado, A.A., \& Chen, I.J. (2008). Inter-organizational communication as a relational competency: Antecedents and performance outcomes in collaborative buyer-supplier relationships. Journal of Operations Management, 26(1), 45-64.

Sung, S.Y. \& Choi, J.N. (2012). Effects of team knowledge management on the creativity and financial performance of organizational teams. Organizational Behavior and Human Decision Processes, 118(1), 4-13.

Terence, R. M., Peter, J.D., Boris, V.K., \& James, R.L. (1988). People in organization: an introduction to organizational behavior in Australia. Journal of Industrial Relations, 31(2), 268270. 